\title{
Identification and localization of proteins associated with the formation of Streptococcus gordonii and Fusobacterium nucleatum biofilms
}

pablo alejandro A Millones-Gómez ( $\nabla$ pablodent@hotmail.com )

Universidad Nacional Mayor de San Marcos https://orcid.org/0000-0002-7105-0940

Reyma Evelyn Bacilio-Amaranto

Universidad Peruana Cayetano Heredia

Dora Maurtua Torres

Universidad Peruana Cayetano Heredia

Patricia Sheen Cortavarría

Universidad Peruana Cayetano Heredia

Yudith Cauna Orocollo

Universidad Peruana Cayetano Heredia

Jaeson Santos Calla Choque

University of California San Diego

Margarita Fe Requena Mendizabal

Universidad Nacional Mayor de San Marcos Facultad de Odontologia

Roger Damaso Calla Poma

Universidad Nacional Mayor de San Marcos Facultad de Odontologia

Research article

Keywords: Fusobacterium nucleatum, coaggregation, oral biofilm, Streptococcus gordonii

Posted Date: January 20th, 2020

DOI: https://doi.org/10.21203/rs.2.21373/v1

License: (c) (i) This work is licensed under a Creative Commons Attribution 4.0 International License.

Read Full License 


\section{Abstract}

Background:To successfully colonize the oral cavity, bacteria must adhere directly or indirectly to the oral surfaces available. Fusobacterium nucleatum plays an important role in the development of the oral biofilm community due to its broad adhesion capabilities, serving as a bridge between the members of the oral biofilm community that cannot be directly joined together. The purpose of this study was to identify and localize the proteins associated with the formation of biofilms of Streptococcus gordonii and F. nucleatum.

Methods: Multispecies biofilms were identified by amplification of the $s i t A$ and $\operatorname{rad} D$ genes by real-time PCR. Biofilm cells cultured with sucrose were counted. The protein concentrations in the membrane and cytoplasmic fractions were quantified by western blot. Results: The proteins HSP40 and GAPDH were detected in the cytoplasmic fraction of biofilm and $F$. nucleatum, respectively. The available anti-GAPDH antibody is specific for GAPDH produced by F. nucleatum, which indicated the coaggregation of $F$. nucleatum on S. gordonii.

Conclusions: HSP40 was only detected in the cytoplasmic fraction of the biofilms, making it one of the essential proteins for adherence. This complex set of interactions could have critical implications for the formation and maturation of oral biofilms in vivo and could provide clues to the mechanism behind the distribution of organisms within the human oral cavity.

\section{Background}

The bacterial species of the human oral cavity depend on their ability to bind to surfaces or to each other for colonization and persistence in this nutrient ecological niche. Therefore, proteins involved in adherence are important components that allow microorganisms to form and reside in complex oral biofilms, in which different groups of bacteria perform specific functions. Although microbial interactions within these biofilms trigger important physiological changes in the associated species, including virulence characteristics, the physical union through specific adhesins is a key element for the successful initiation of surface colonization and biofilm integration [1, 2].

Species of the genus Fusobacterium have been linked to a wide variety of microbial species and are considered important for the formation and architecture of biofilms. Fusobacteria integrate into biofilms by binding to early colonists attached to the surface, such as streptococci and actinomycetes. In addition, fusobacteria recruit other bacterial species, including early colonizers and important periodontal pathogens that cannot directly attach to surfaces. This characteristic allows them to promote changes in the microbial community and impacts their pathogenesis [2].

Culturable oral fusobacteria are predominantly F. periodonticum and F. nucleatum. While F. periodonticum encompasses only one species, F. nucleatum includes five subspecies: nucleatum, polymorphum, fusiforme, animalis, and vincentii. This group of microorganisms thrives not only in subgingival 
environments [3,4] but also in the supragingival plaque [5]. Streptococci are the most common early colonizers and constitute the main binding partner for the recruitment of fusobacteria in oral biofilms [6].

Bacterial interspecies interactions mediated by adherence are important elements in the formation of oral biofilms. These interactions often occur at a species-specific level, which could determine the health or disease association of a biofilm community. Among the key actors involved in these processes are the fusobacteria that have been recognized for their ability to interact with numerous bacterial groups.

The oral cavity is a great model system for studying polymicrobial interactions since it is home to more than 600 different recognized species of bacteria, most of which are considered to be commensal bacteria [7-10]. Microorganisms in oral biofilms have been categorized into early and late colonizers. The first colonizing species are mainly gram-positive, capable of adhering directly to the surface of the tooth and forming the basal layers of the oral biofilm [11-13]. Late colonizers are mainly gram-negative bacteria, including certain periodontal pathogens such as Treponema denticola, Tannerella forsythia,and Porphyromonas gingivalis,as well as other bacteria within the oral biofilm, forming a complex network of direct or indirect interactions. The spatial distribution of different bacterial species is important in the formation and architecture of oral biofilms. Many of the known oral bacterial species do not directly interact with each other; instead, they interact indirectly through their mutual union with F. nucleatum [14].

F. nucleatum is a gram-negative fusiform anaerobic bacterium that has been associated with periodontal disease and a number of systemic diseases. It is considered a "bridge organism" due to its ability to form a colonization bridge between species that do not interact directly, thus playing an integral role in the formation of a mature dental plaque. The physical attachment between the interacting species is mediated by specific cellular adhesion proteins in their outer membranes [15]. For example, proteins of the SitA family that anchor to the cell wall have been identified, such as SspA/SspB of S. gordonii, which allow interactions with other streptococci and other oral species, including Porphyromonas gingivalis, Actinomyces, and Candida [16-19]. Egland et al. [20] showed that the SspA/SspB homologue of $S$. mutans binds to the host's saliva proteins; the host's matrix proteins, including type I collagen, fibronectin, laminin, and keratin; and serum components such as fibrinogen. Certain strains of actinomycetes can be recognized by the expression of the SpaP protein in S. gordonii along with CshA, a protein typically not present in S. mutans [21].

Recently, fusobacterial interactions with Streptococcus, an important oral carcinogenic pathogen, have been described, but most of the studies focussed on binding to non-mutant streptococci, and paired specific adhesins have not yet been identified [22-25]. The purpose of this study was to identify the proteins linked to the adhesion and coaggregation of microorganisms of the species $F$. nucleatum and $S$. gordonii. In this way, possible targets for future therapies that block the incorporation of pathogenic bacteria can be found and can be used as the first biomarkers of oral diseases.

\section{Methods}




\section{Culture and bacterial strains}

Strains of S. gordonii (ATCC 51656) and F. nucleatum (ATCC 10953) were used, characterized by biofilm formation in addition to playing an important role in periodontal disease. Tryptic soy broth (TSB), $30 \mathrm{~g} / \mathrm{L}$ of distilled water, was used as culture medium, to which artificial saliva ( $350 \mathrm{~mL}$ of distilled water with $3.15 \mathrm{~g}$ of $\mathrm{NaCl}$ ), a solution of $4 \%$ carboxymethyl cellulose (4 grams of carboxymethyl cellulose in $100 \mathrm{~mL}$ of distilled water), and $50 \mathrm{~mL}$ of glycerine were added. A final volume of $500 \mathrm{~mL}$ was obtained, autoclaved, and stored at $4{ }^{\circ} \mathrm{C}$.

\section{Formation of multispecies biofilm}

The biofilm was formed on the surface of $25 \mathrm{~mm} \times 75 \mathrm{~mm}$ transparent rectangular slides placed in $90 \times$ $15 \mathrm{~mm}$ Petri dishes, one Petri dish per slide. Biofilms were incubated under anaerobic conditions at $37^{\circ} \mathrm{C}$ using AnaeroGen sachets in $2.5 \mathrm{~L}$ jars (12-Petri-dish capacity) for 24 hours (time 1), 5 days (time 2), 7 days (time 3 ), or 10 days (time 4).

A colony of each strain was inoculated in $15 \mathrm{~mL}$ of TSB at $37^{\circ} \mathrm{C}$ in anaerobiosis until reaching the exponential growth phase of each strain: an optical density at $550 \mathrm{~nm}$ of 0.125 (McFarland 0.5 scale), which equals $150 \times 10^{6} \mathrm{cells} / \mathrm{mL}$, which took 4.5 hours for $S$. gordonii and 8 hours for $F$. nucleatum. The sterile slides were then incubated in Petri dishes with $16 \mathrm{~mL}$ of sterile artificial saliva and tempered for 4 hours at $37{ }^{\circ} \mathrm{C}$. The slides were removed with sterile tweezers and washed gently with $15 \mathrm{~mL}$ of phosphate-buffered saline (PBS) (pH 7.0, tempered) with a sterile $10 \mathrm{~mL}$ pipette, and the slides were placed in new sterile Petri dishes. Then, $100 \mu \mathrm{L}$ of $S$. gordonii culture was added to each slide and incubated for 1 hour at $37^{\circ} \mathrm{C}$. Next, $100 \mu \mathrm{L}$ of the culture of $F$. nucleatum was added and incubated for 1 hour at $37^{\circ} \mathrm{C}$. Sixteen millilitres of TSB $\left(37^{\circ} \mathrm{C}\right)$ was added to the slides and incubated at $37^{\circ} \mathrm{C}$ for $1,5,7$, or 10 days.

\section{Verification of the presence of both bacteria}

Genomic DNA was extracted from S. gordonii and F. nucleatum biofilms, pooled, and separately cultivated. To verify the specificity of the sitA and radD primers, conventional PCR was first performed, adding the $F$. nucleatum genome to the reaction with the srtA primers and the $S$. gordonii genome to the reaction with the radD primers. (Figure 1) Once the specificity was verified, real-time PCR was run, performing reactions with the srtA primers and $S$. gordonii genome, radD primers and the $F$. nucleatum genome, srtA+radD primers and the biofilm (S. gordonii and F. nucleatum) genome, and srtA and radD primers separately to amplify these genes in the biofilm genome.(figure $2,3,4$ )

\section{Quantification of F. nucleatum and S. gordonii cells}


Genomic DNA was extracted from the cultured biofilms at 2.5\% after 1 day, 4 days, 7 days, and 10 days. The DNA concentration was quantified, and for absolute quantification by real-time PCR, $100 \mathrm{ng} / \mu \mathrm{L}$ was used for all samples to determine the proportion of cells from both species. The oligonucleotides used were sitA F: 5' TATTATGGTGCTGGTACGATGAAAGAGACTC 3' and sitA R: 5' TATAGATTTTCATACCAGCCTTAGCACGATC $3^{\prime}$ for $S$. gordonii and radD F: $5^{\prime}$ GGATTTATCTTTGCTAATTGGGGAAATTATAG 3' and radD R: 5' ACTATTCCATATTCTCCATAATATTTCCCATTAGA 3' for F. nucleatum.

\section{Separation and quantification of proteins of the membrane and cytoplasmic fractions}

The cells were detached from the glass surface of the Petri dishes with by incubating them in trypsin at $37^{\circ} \mathrm{C}$ for 15 minutes and were harvested by centrifugation at $5000 \times \mathrm{g}$ for 10 minutes at $4{ }^{\circ} \mathrm{C}$. The cell pellet was washed with $1 \times$ PBS pH 7.4. The pellet was resuspended in lysis buffer (50 mM HEPES, $8 \mathrm{M}$ urea, and $1 \mathrm{mM}$ dithiothreitol) and incubated at $95^{\circ} \mathrm{C}$ for 5 minutes. Immediately, the tubes were put on ice, and the cells were lysed by sonication (power of $0.6 \mathrm{~W}$, three 30 -second sonications, kept on ice for 3 minutes between sonications). Cellular debris was pelleted by centrifugation at $720 \times \mathrm{g}$ for 7 minutes at 4 ${ }^{\circ} \mathrm{C}$, and then the supernatant was collected and centrifuged at $10,000 \times \mathrm{g}$ for 10 minutes at $4{ }^{\circ} \mathrm{C}$ to pellet the membrane fraction. The supernatant was recovered, from which cytoplasmic proteins were precipitated with absolute ethanol. Five volumes of absolute ethanol, previously cooled, was added to the pellet and left at $-70^{\circ} \mathrm{C}$ for 2 hours. Proteins were obtained by centrifugation at $17,000 \times \mathrm{g}$ for 45 minutes at $4{ }^{\circ} \mathrm{C}$, and the pellet was resuspended with lysis buffer. Finally, the proteins were quantified by the Bradford method using a standard curve of known concentrations for bovine serum albumin.

\section{Precipitation of cytoplasmic proteins}

Two methods were used, with acetone and ethanol. The acetone method consisted of adding 5 volumes of $100 \%$ acetone in $100 \mu \mathrm{L}$ of sample and leaving at $-20^{\circ} \mathrm{C}$ for 3 hours. The proteins were obtained by centrifugation at $15,000 \times \mathrm{g}$ for 20 minutes at $4{ }^{\circ} \mathrm{C}$. The supernatant was discarded, and the pellet was washed with $50 \%$ acetone twice with centrifugation intervals at $15,000 \times \mathrm{g}$ for 20 minutes at $4{ }^{\circ} \mathrm{C}$. The ethanol method consisted of adding volumes of previously cooled absolute ethanol and leaving it at -70 ${ }^{\circ} \mathrm{C}$ for 2 hours. The proteins were obtained by centrifugation at $17,000 \times \mathrm{g}$ for 45 minutes at $4{ }^{\circ} \mathrm{C}$. The proteins were quantified by the Bradford method and separated by $12 \%$ sodium dodecyl sulfatepolyacrylamide gel electrophoresis).

\section{Immunodetection of HSP60 by western blot}

After separating the membrane or cytoplasmic proteins by $12 \%$ SDS-PAGE, the proteins were transferred to nitrocellulose membranes. The membranes were washed with $1 \times \mathrm{PBS} \mathrm{pH} 7.4$ three times. Then, a 
general protein block was performed with $5 \%$ milk with incubation at $37^{\circ} \mathrm{C}$ for 1 hour in constant motion. The membrane was washed with PBS plus $0.05 \%$ Tween 20 at room temperature three times. Immunodetection was performed with the anti-HSP60 antibody generated in mice (1:1000 dilution, in 5\% milk) and incubated at $37^{\circ} \mathrm{C}$ for 1 hour. The antibody-antigen complex was detected by incubating the membrane with rabbit anti-mouse IgG antibody conjugated with horseradish peroxidase (1:2000 dilution, in $5 \%$ milk) at $37^{\circ} \mathrm{C}$ for 1 hour. The membrane was washed again to remove excess antibodies and finally developed with diaminobenzidine plus $\mathrm{H}_{2} \mathrm{O}_{2}$.

\section{Results}

The protein profile of S. gordonii and F. nucleatum from individual cultures run in one-dimensional electrophoresis revealed that some proteins were only found in S. gordonii and not in F. nucleatum, and vice versa (Figure 5, red and yellow arrows). Ct and inverse-proportional Ct values determined for the exposed S. gordonii and F. nucleatum biofilms.(table 1)

The cytoplasmic protein profile of the biofilms harvested after 1, 4, 7, and 10 days of culture kept constant over time and was similar to the profile of the individual culture of S. gordonii. However, a higher protein load was observed between 50 and $37 \mathrm{kDa}$ (Figure 6), suggesting the presence of F. nucleatum proteins. On the other hand, no drastic changes were observed in the production of any particular protein from either S. gordonii or F. nucleatum.

Through the detection of GAPDH using a specific antibody, it was determined that the antibody only detected an epitope that is found in GAPDH of F. nucleatum and not of S. gordonii (Figure 7a). Its molecular weight ranged between 50 and $37 \mathrm{kDa}$. In biofilms, on days 1 and 4 the detection was quite faint compared to at 7 and 10 days (Figure $7 b$ ), confirming that the adherence of F. nucleatum on $\mathrm{S}$. gordonii was gradual and definitive at 7 days of culture.

The protein HSP40 was not detected in individual cultures (Figure 8a), but it was detected in biofilms after 7 and 10 days of culture, its molecular weight ranging from 50 to $37 \mathrm{kDa}$ (Figure 8b), indicating that protein is involved in coaggregation and therefore in biofilm formation.

\section{Discussion}

The oral cavity is a complex bacterial ecosystem composed of multiple microorganisms that intimately coexist [26-30]. Biofilms are one way they coexist [31,32], and they develop thanks to multiple mechanisms associated with protein expression [33-37]. However, the literature on this subject is still scarce $[18,37,38]$. In this study, we sought to identify proteins associated with the formation of biofilms and whether these proteins are found in the membranes or in the cytoplasm of F. nucleatum and $S$. gordonii biofilms.

The role of proteins in the adherence and coaggregation of microorganisms in biofilms has been demonstrated in two studies $[39,40]$ showing the overexpression of biofilm growth-related proteins such 
as the ATP-binding cassette $[41,42]$. These membrane proteins are fundamental to many biological processes, such as cell division, control of cell volume, and control of which substances pass through the cell membrane. These results may be relevant because of the role of these proteins in the bacterial resistance to antibiotics [42-46].

A group of proteins that were mostly overexpressed in the biofilm were proteins of unknown function called hypothetical proteins [47]. These data are in line with what has been described by other authors $[48,49]$. The analysis of these proteins and of their roles in biofilm can provide information on the role of this bacterium in this form of growth [50]. Another protein that is overexpressed in biofilm and may be of interest is NusG [51]. This protein can be used as a marker of $F$. nucleatum [52] and may be relevant for the development of new diagnostic tools $[52,53]$ not only for periodontitis but also for other diseases associated with the presence of the two microorganisms studied in this paper.

\section{Conclusions}

The proteins HSP40 and GAPDH were detected in the cytoplasmic fraction of the biofilm and in $F$. nucleatum, respectively. The available anti-GAPDH antibody is specific for GAPDH produced by $F$. nucleatum, so our findings indicate the coaggregation of F. nucleatum on S. gordonii. The HSP40 protein was only detected in the cytoplasmic fraction of the biofilms, being one of the essential proteins for adherence.

\section{List Of Abbreviations}

BHI: Brain heart infusion; DNA: deoxyribonucleic acid; PCR: polymerase chain reaction; S. gordonii: Streptococcus gordonii; F. nucleatum. Fusobacterium nucleatum; SDS-PAGE: sodium dodecylsulphatepolyacrylamide gel electrophoresis.

\section{Declarations}

\section{Ethics approval and consent to participate}

Not applicable.

\section{Consent for publication}

Not applicable.

\section{Availability of data and materials}

The datasets generated and/or analyzed during the current study are available from the corresponding author on reasonable request. 
The authors declare that they have no competing interests.

\section{Funding}

This work was supported by Grants from the Alas Peruanas University

\section{Authors' contributions}

All authors read and approved the final version of this manuscript.

\section{Acknowledgements}

Not applicable.

\section{References}

1.Guo L, He X, Shi W. Intercellular communications in multispecies oral microbial communities. Front Microbiol. 2014;5:328.

2.Kolenbrander PE, Palmer RJ, Jr., Periasamy S, Jakubovics NS. Oral multispecies biofilm development and the key role of cell-cell distance. Nat Rev Microbiol. 2010;8:471-80.

3.Kook JK, Park SN, Lim YK, Choi MH, Cho E, Kong SW, et al. Fusobacterium nucleatum subsp. fusiforme Gharbia and Shah 1992 is a later synonym of Fusobacterium nucleatum subsp. vincentii Dzink et al. 1990. Curr Microbiol. 2013;66:414-7.

4.Aruni AW, Dou Y, Mishra A, Fletcher HM. The biofilm community-rebels with a cause. Curr Oral Health Rep. 2015;2:48-56.

5.Haffajee AD, Socransky SS, Patel MR, Song X. Microbial complexes in supragingival plaque. Oral Microbiol Immunol. 2008;23:196-205.

6.Kaplan CW, Lux R, Haake SK, Shi W. The Fusobacterium nucleatum outer membrane protein RadD is an arginine-inhibitable adhesin required for inter-species adherence and the structured architecture of multispecies biofilm. Mol Microbiol. 2009;71:35-47.

7. Handley PS, Carter PL, Wyatt JE, Hesketh LM. Surface structures (peritrichous fibrils and tufts of fibrils) found on Streptococcus sanguis strains may be related to their ability to coaggregate with other oral genera. Infect Immun. 1985;47:217-27.

8.Back CR, Douglas SK, Emerson JE, Nobbs AH, Jenkinson HF. Streptococcus gordonii DL1 adhesin SspB $\mathrm{V}$-region mediates coaggregation via receptor polysaccharide of Actinomyces oris T14V. Mol Oral Microbiol. 2015;30:411-24. 
9.Brooks W, Demuth DR, Gil S, Lamont RJ. Identification of a Streptococcus gordonii SspB domain that mediates adhesion to Porphyromonas gingivalis. Infect Immun. 1997;65:3753-8.

10.Jakubovics NS, Stromberg N, van Dolleweerd CJ, Kelly CG, Jenkinson HF. Differential binding specificities of oral streptococcal antigen I/II family adhesins for human or bacterial ligands. Mol Microbiol. 2005;55:1591-605.

11.Dewhirst FE, Chen T, Izard J, Paster BJ, Tanner AC, Yu WH, et al. The human oral microbiome. J Bacteriol. 2010;192:5002-17.

12.Aas JA, Paster BJ, Stokes LN, Olsen I, Dewhirst FE. Defining the normal bacterial flora of the oral cavity. J Clin Microbiol. 2005;43:5721-32.

13.Kolenbrander PE, London J. Adhere today, here tomorrow: oral bacterial adherence. J Bacteriol. 1993;175:3247-52.

14.Kaplan A, Kaplan CW, He X, McHardy I, Shi W, Lux R. Characterization of aid1, a novel gene involved in Fusobacterium nucleatum interspecies interactions. Microb Ecol. 2014;68:379-87.

15. He J, Bao Y, Li J, Qiu Z, Liu Y, Zhang X. Nanocomplexes of carboxymethyl chitosan/amorphous calcium phosphate reduce oral bacteria adherence and biofilm formation on human enamel surface. $J$ Dent. 2019;80:15-22.

16.Ebersole JL, Peyyala R, Gonzalez OA. Biofilm-induced profiles of immune response gene expression by oral epithelial cells. Mol Oral Microbiol. 2019;34. doi: 10.1111/omi.12251.

17.Neilands J, Davies JR, Bikker FJ, Svensater G. Parvimonas micra stimulates expression of gingipains from Porphyromonas gingivalis in multi-species communities. Anaerobe. 2019;55:54-60.

18.Mutha NVR, Mohammed WK, Krasnogor N, Tan GYA, Choo SW, Jakubovics NS. Transcriptional responses of Streptococcus gordonii and Fusobacterium nucleatum to coaggregation. Mol Oral Microbiol. 2018;33:450-64.

19.Tsutsumi K, Maruyama M, Uchiyama A, Shibasaki K. Characterisation of a sucrose-independent in vitro biofilm model of supragingival plaque. Oral Dis. 2018;24:465-75.

20.Egland PG, Du LD, Kolenbrander PE. Identification of independent Streptococcus gordonii SspA and SspB functions in coaggregation with Actinomyces naeslundii. Infect Immun. 2001;69:7512-6.

21.Zhou P, Li X, Huang IH, Qi F. Veillonella catalase protects the growth of fusobacterium nucleatum in microaerophilic and Streptococcus gordonii-resident environments. Appl Environ Microbiol. 2017;83:e01079-17. 
22.Lima BP, Shi W, Lux R. Identification and characterization of a novel Fusobacterium nucleatum adhesin involved in physical interaction and biofilm formation with Streptococcus gordonii. Microbiologyopen. 2017;6. doi: 10.1002/mbo3.444.

23.Shimazu K, Oguchi R, Takahashi Y, Konishi K, Karibe H. Effects of surface reaction-type pre-reacted glass ionomer on oral biofilm formation of Streptococcus gordonii. Odontology. 2016;104:310-7.

24.Wang HY, Cheng JW, Yu HY, Lin L, Chih YH, Pan YP. Efficacy of a novel antimicrobial peptide against periodontal pathogens in both planktonic and polymicrobial biofilm states. Acta Biomater. 2015;25:15061.

25.Sakanaka A, Kuboniwa M, Takeuchi H, Hashino E, Amano A. Arginine-Ornithine Antiporter ArcD controls arginine metabolism and interspecies biofilm development of Streptococcus gordonii. J Biol Chem. 2015;290:21185-98.

26. Hendrickson EL, Wang T, Beck DA, Dickinson BC, Wright CJ, J Lamont R, et al. Proteomics of Fusobacterium nucleatum within a model developing oral microbial community. Microbiologyopen. 2014;3:729-51.

27.Jang YJ, Sim J, Jun HK, Choi BK. Differential effect of autoinducer 2 of Fusobacterium nucleatum on oral streptococci. Arch Oral Biol. 2013;58:1594-602.

28.Peyyala R, Kirakodu SS, Novak KF, Ebersole JL. Oral epithelial cell responses to multispecies microbial biofilms. J Dent Res. 2013;92:235-40.

29.Ben Lagha A, LeBel G, Grenier D. Tart cherry (Prunus cerasus L.) fractions inhibit biofilm formation and adherence properties of oral pathogens and enhance oral epithelial barrier function. Phytother Res. 2019; doi: 10.1002/ptr.6574.

30.Horiuchi A, Kokubu E, Warita T, Ishihara K. Synergistic biofilm formation by Parvimonas micra and Fusobacterium nucleatum. Anaerobe. 2019:102100. doi: 10.1016/j.anaerobe.2019.102100.

31.Thurnheer T, Karygianni L, Flury M, Belibasakis GN. Fusobacterium species and subspecies differentially affect the composition and architecture of supra- and subgingival biofilms models. Front Microbiol. 2019;10:1716.

32.Lima BP, Hu LI, Vreeman GW, Weibel DB, Lux R. The oral bacterium Fusobacterium nucleatum binds staphylococcus aureus and alters expression of the staphylococcal accessory regulator sarA. Microb Ecol. 2019;78:336-47.

33.Zhou Y, Millhouse E, Shaw T, Lappin DF, Rajendran R, Bagg J, et al. Evaluating Streptococcus mutans strain dependent characteristics in a polymicrobial biofilm community. Front Microbiol. 2018;9:1498. 
34.Arenas Rodrigues VA, de Avila ED, Nakano V, Avila-Campos MJ. Qualitative, quantitative and genotypic evaluation of Aggregatibacter actinomycetemcomitans and Fusobacterium nucleatum isolated from individuals with different periodontal clinical conditions. Anaerobe. 2018;52:50-8.

35.Wu C, Al Mamun AAM, Luong TT, Hu B, Gu J, Lee JH, et al. Forward genetic dissection of biofilm development by Fusobacterium nucleatum: novel functions of cell division proteins FtsX and EnvC. mBio. 2018;9:e00360-18.

36.Couvigny B, Kulakauskas S, Pons N, Quinquis B, Abraham AL, Meylheuc T, et al. Identification of new factors modulating adhesion abilities of the pioneer commensal bacterium streptococcus salivarius. Front Microbiol. 2018;9:273.

37.Ahn SH, Chun S, Park C, Lee JH, Lee SW, Lee TH. Transcriptome profiling analysis of senescent gingival fibroblasts in response to Fusobacterium nucleatum infection. PLoS One. 2017;12:e0188755.

38.Matos AO, Ricomini-Filho AP, Beline T, Ogawa ES, Costa-Oliveira BE, de Almeida AB, et al. Three-species biofilm model onto plasma-treated titanium implant surface. Colloids Surf B Biointerfaces. 2017;152:354-66.

39.Song WS, Lee JK, Park SH, Um HS, Lee SY, Chang BS. Comparison of periodontitis-associated oral biofilm formation under dynamic and static conditions. J Periodontal Implant Sci. 2017;47:219-30.

40.Mohammed MMA, Pettersen VK, Nerland AH, Wiker HG, Bakken V. Quantitative proteomic analysis of extracellular matrix extracted from mono- and dual-species biofilms of Fusobacterium nucleatum and Porphyromonas gingivalis. Anaerobe. 2017;44:133-42.

41.Stephen AS, Millhouse E, Sherry L, Aduse-Opoku J, Culshaw S, Ramage G, et al. In vitro effect of Porphyromonas gingivalis methionine gamma lyase on biofilm composition and oral inflammatory response. PLoS One. 2016;11:e0169157.

42.Guo L, Shokeen B, He X, Shi W, Lux R. Streptococcus mutans SpaP binds to RadD of Fusobacterium nucleatum ssp. polymorphum. Mol Oral Microbiol. 2017;32:355-64.

43.Peyyala R, Emecen-Huja P, Ebersole JL. Environmental lead effects on gene expression in oral epithelial cells. J Periodontal Res. 2018;53:961-71.

44.Song Y, He JZ, Wang RK, Ma JZ, Zou L. Effect of SrtA on interspecies adherence of oral bacteria. Curr Med Sci. 2018;38:160-6.

45.Wang H, Ai L, Zhang Y, Cheng J, Yu H, Li C, et al. The effects of antimicrobial peptide Nal-P-113 on inhibiting periodontal pathogens and improving periodontal status. Biomed Res Int. 2018;2018:1805793.

46.Izui S, Sekine S, Maeda K, Kuboniwa M, Takada A, Amano A, et al. Antibacterial activity of curcumin against periodontopathic bacteria. J Periodontol. 2016;87:83-90. 
47.Park JH, Lee JK, Um HS, Chang BS, Lee SY. A periodontitis-associated multispecies model of an oral biofilm. J Periodontal Implant Sci. 2014;44:79-84.

48.Wang Q, Wright CJ, Dingming $\mathrm{H}$, Uriarte SM, Lamont RJ. Oral community interactions of Filifactor alocis in vitro. PLoS One. 2013;8:e76271.

49. Hendrickson EL, Wang T, Dickinson BC, Whitmore SE, Wright CJ, Lamont RJ, et al. Proteomics of Streptococcus gordonii within a model developing oral microbial community. BMC Microbiol. 2012;12:211.

50.Obata J, Fujishima K, Nagata E, Oho T. Pathogenic mechanisms of cariogenic Propionibacterium acidifaciens. Arch Oral Biol. 2019;105:46-51.

51.Cawley A, Golding S, Goulsbra A, Hoptroff M, Kumaran S, Marriott R. Microbiology insights into boosting salivary defences through the use of enzymes and proteins. J Dent. 2019;80 Suppl 1:S19-S25.

52.Bao K, Bostanci N, Thurnheer T, Grossmann J, Wolski WE, Thay B, et al. Aggregatibacter actinomycetemcomitans $\mathrm{H}$-NS promotes biofilm formation and alters protein dynamics of other species within a polymicrobial oral biofilm. NPJ Biofilms Microbiomes. 2018;4:12.

53. Hutcherson JA, Sinclair KM, Belvin BR, Gui Q, Hoffman PS, Lewis JP. Amixicile, a novel strategy for targeting oral anaerobic pathogens. Sci Rep. 2017;7:10474.

\section{Table}

Table 1. Ct and inverse-proportional Ct values determined for the exposed S. gordonii and F. nucleatum biofilms. 


\begin{tabular}{|c|c|c|}
\hline & Ct & $1 / \mathrm{Ct}$ \\
\hline \multirow[t]{4}{*}{ S. gordonii srtA } & 19.757 & 0.051 \\
\hline & 21.528 & 0.046 \\
\hline & 21.714 & 0.046 \\
\hline & 22.189 & 0.045 \\
\hline \multirow[t]{4}{*}{ F. nucleatum radD } & 19.554 & 0.051 \\
\hline & 24.739 & 0.040 \\
\hline & 20.429 & 0.049 \\
\hline & 27.758 & 0.036 \\
\hline \multirow[t]{4}{*}{$\mathrm{F}+\mathrm{S} s \mathrm{st} A+\mathrm{rad} D$} & 27.133 & 0.037 \\
\hline & 22.179 & 0.045 \\
\hline & 21.647 & 0.046 \\
\hline & 16.732 & 0.060 \\
\hline \multirow[t]{4}{*}{$\mathrm{F}+\mathrm{S}$ srtA } & 36.687 & 0.027 \\
\hline & 25.809 & 0.039 \\
\hline & 22.192 & 0.045 \\
\hline & 16.638 & 0.060 \\
\hline \multirow[t]{4}{*}{$\mathrm{F}+\mathrm{S}$ radD } & 30.418 & 0.033 \\
\hline & 32.55 & 0.031 \\
\hline & 30.588 & 0.033 \\
\hline & 0 & nd \\
\hline
\end{tabular}

Figures 


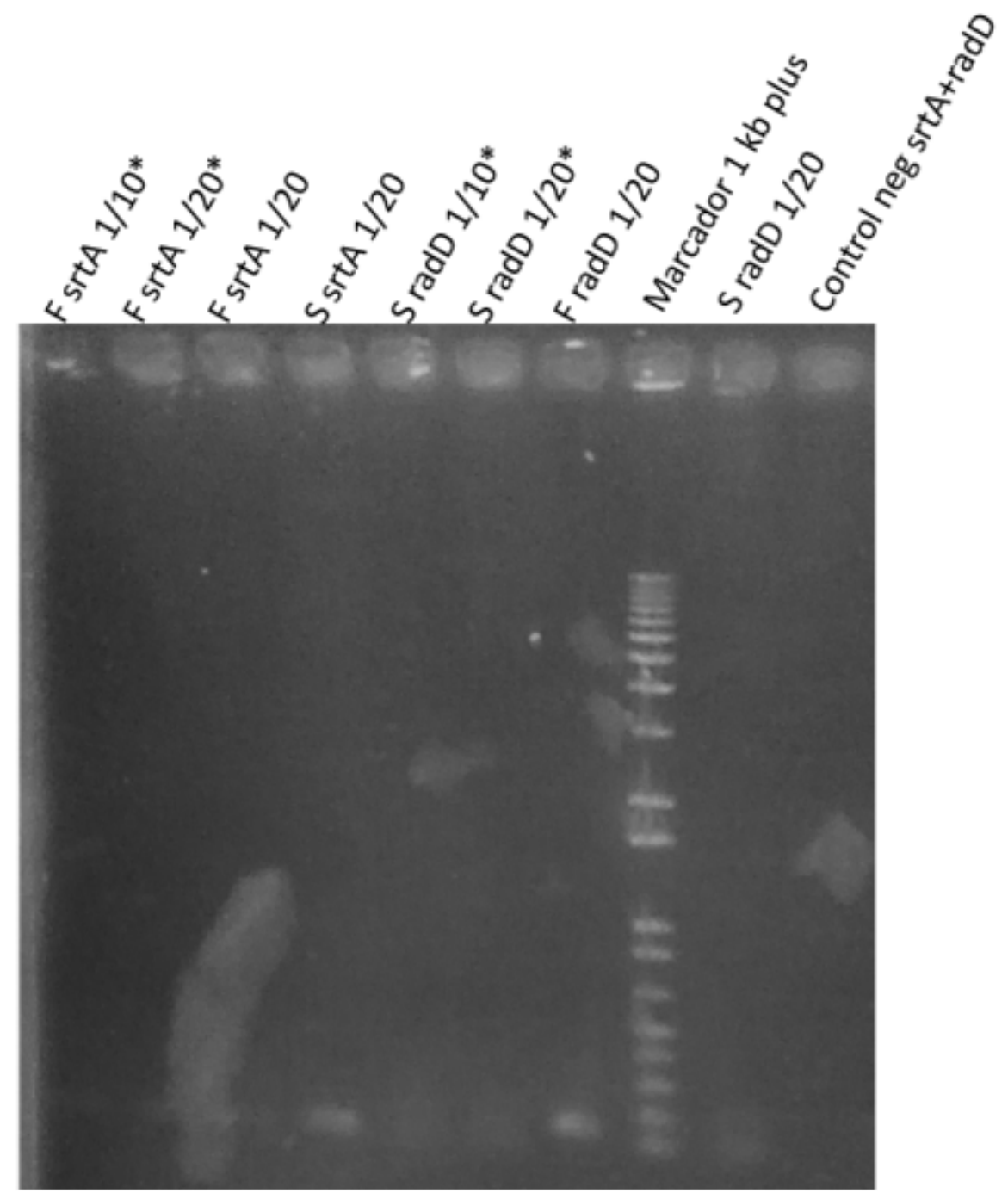

\section{Figure 1}

Figure 1

Electrophoresis using sitA and radD from F. nucleatum and S. gordonii. 

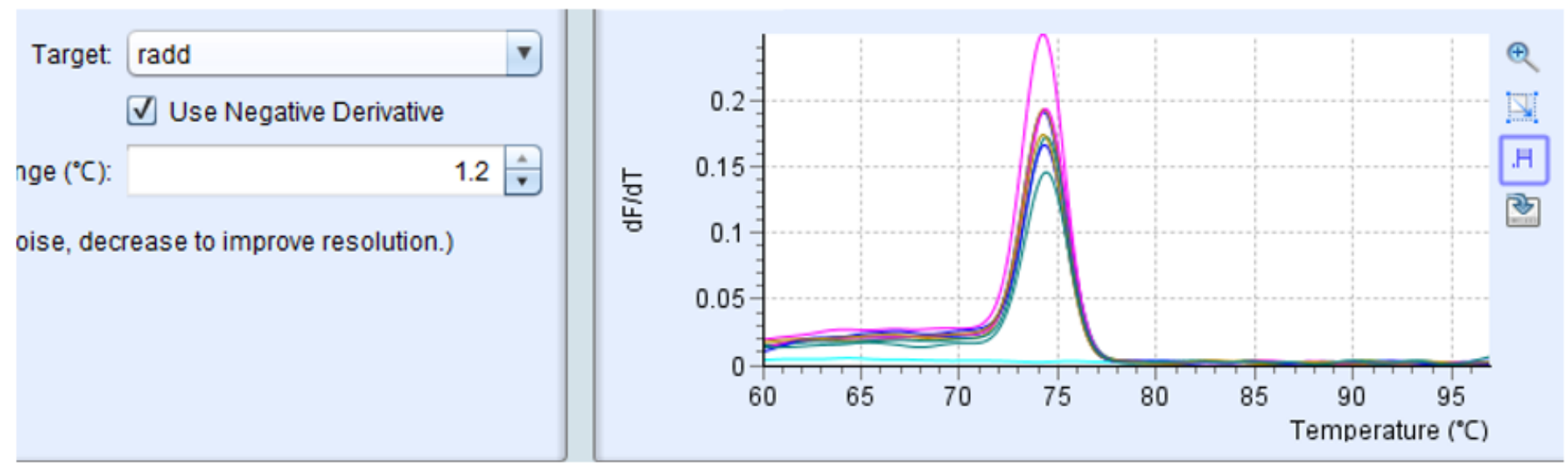

\section{Figure 2}

\section{Figure 2}

Tm curve of radD

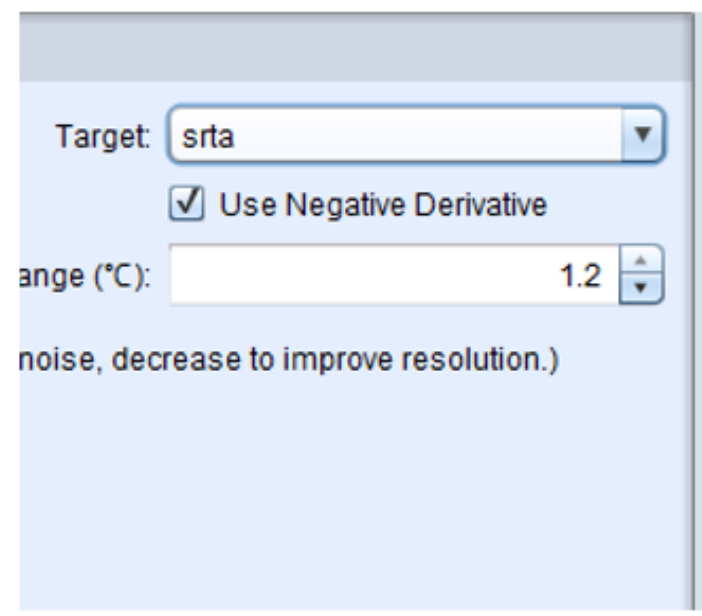

\section{\begin{tabular}{l|ll} 
Melt Peaks Melt Curve & Notes
\end{tabular}}

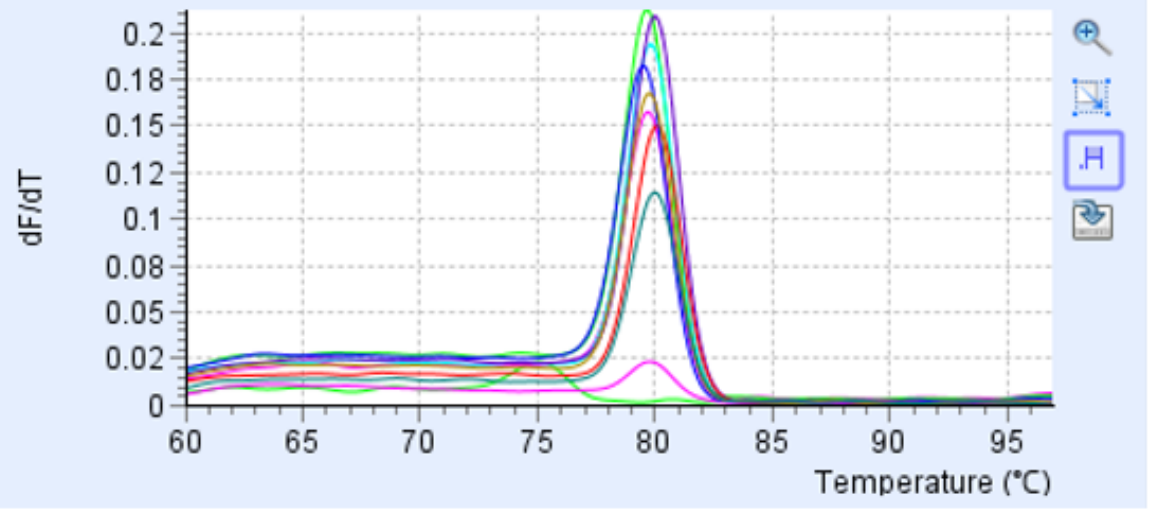

\section{Figure 3}

Figure 3

Tm curve of srtA 


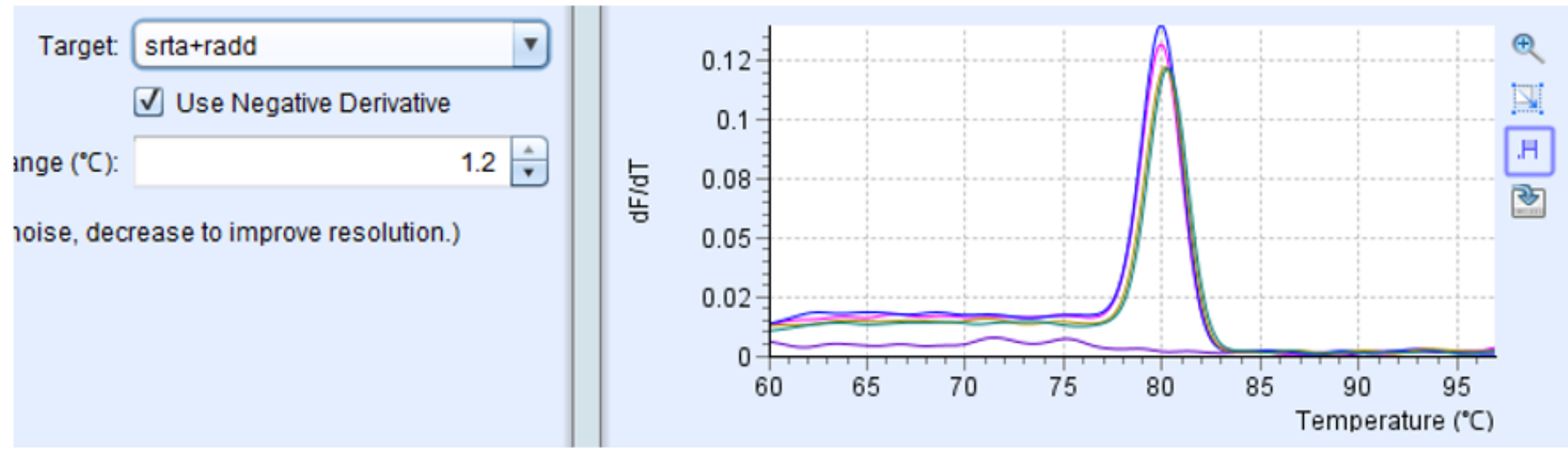

\section{Figure 4}

Figure 4

Tm curve of sitA+radD 


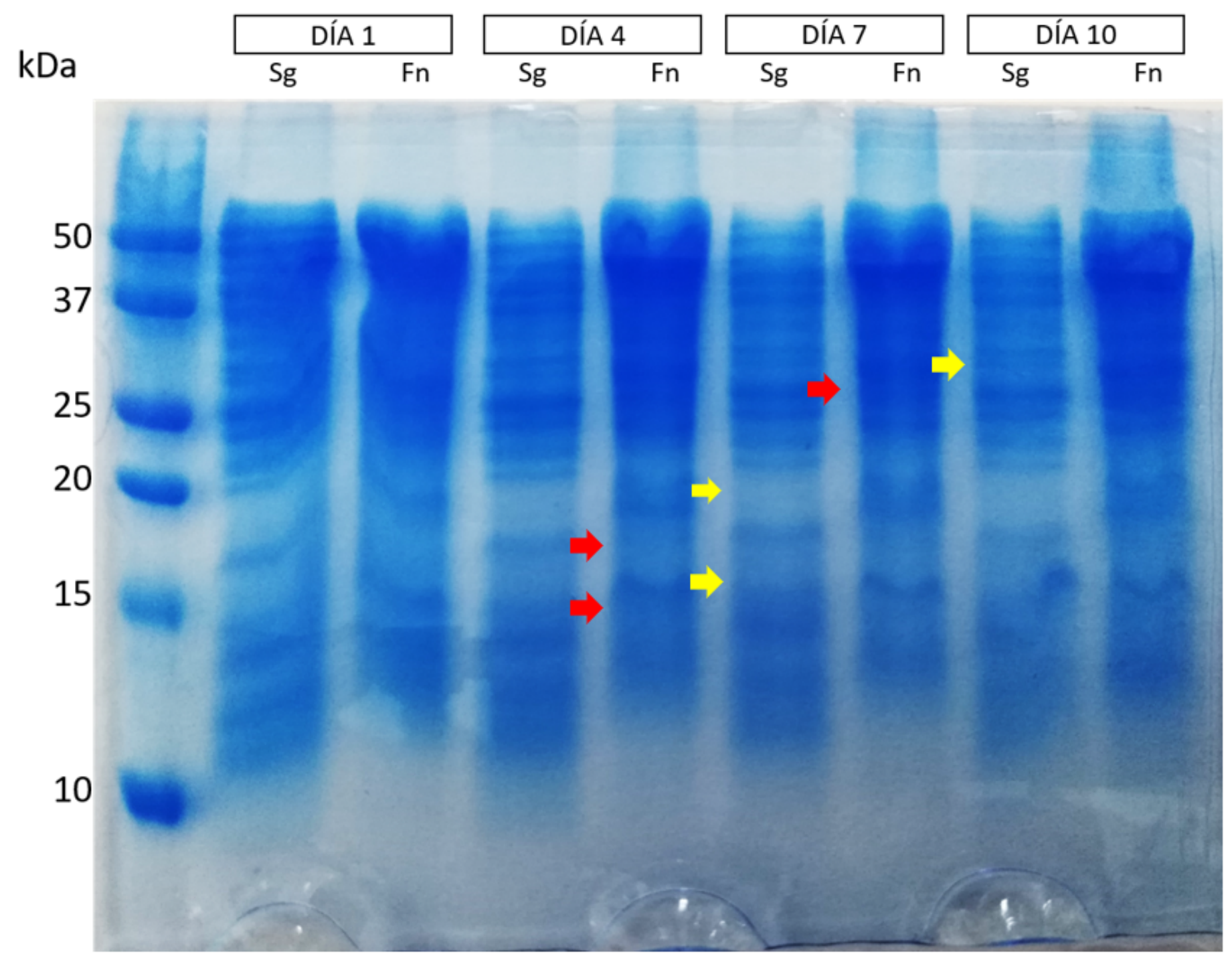

\section{Figure 5}

\section{Figure 5}

SDS-PAGE of proteins of the cytoplasmic fraction of individual cultures 


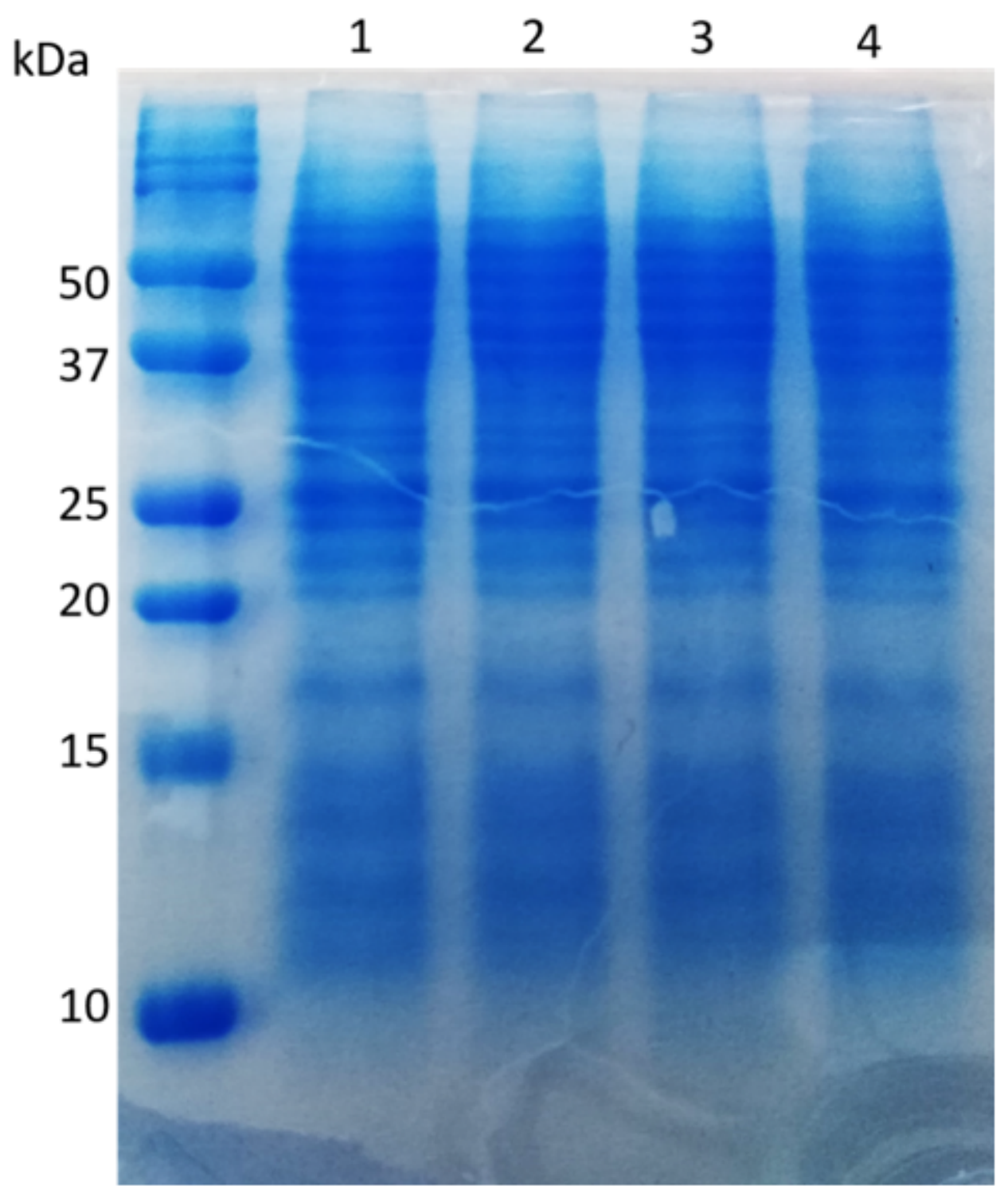

\section{Figure 6}

\section{Figure 6}

SDS-PAGE of proteins of the cytoplasmic fraction of the S. gordonii and F. nucleatum biofilm 


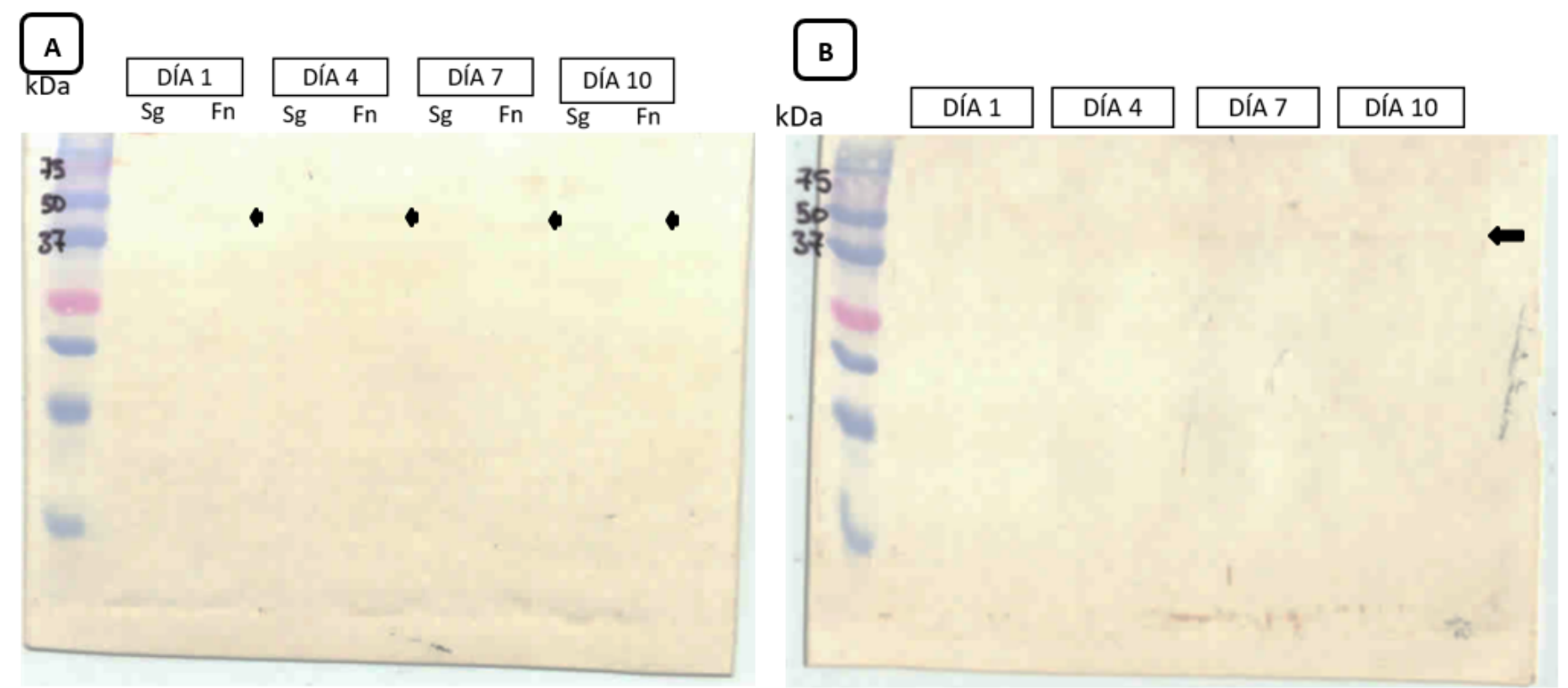

Figure 7

\section{Figure 7}

Immunodetection of GAPDH in the cytoplasmic fraction of individual cultures and biofilm
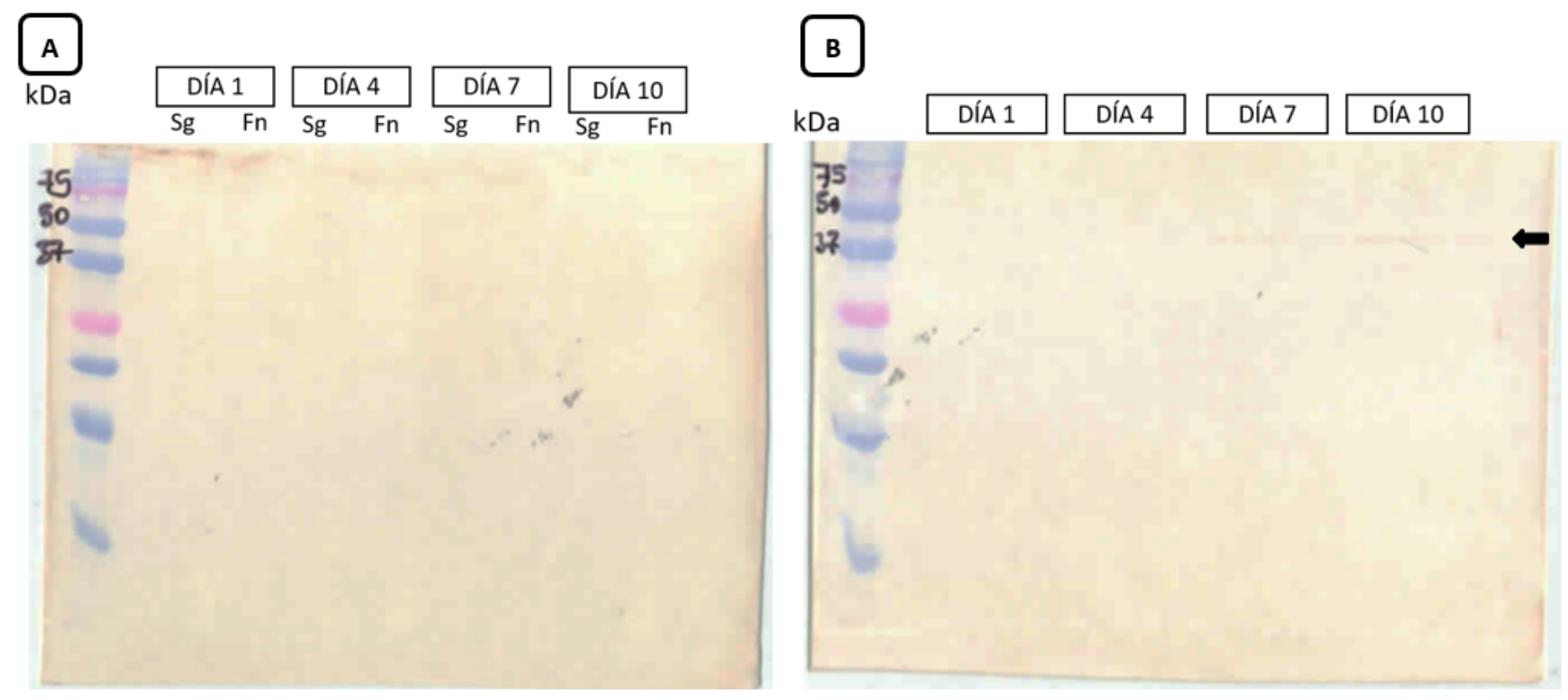

Figure 8

Figure 8

Immunodetection of HSP40 in the cytoplasmic fraction of individual cultures and the biofilm 